\title{
A Cobertura da Guerra de Angola pelos jornais Brasileiros
}

\section{Coverage of the Angolan War by Brazilian newspapers}

DOI: $10.46814 /$ lajdv2n5-014

Recebimento dos originais: 10/07/2020

Aceitação para publicação: 30/08/2020

\section{Magdala Azulay Teixeira Vaz Borja}

Graduada em Jornalismo pela Universidade de Fortaleza (UNIFOR). Pós-Graduada em Assessoria de Comunicação da UNIFOR e do curso de Pós-Graduação em Teorias da Comunicação e da Imagem da Universidade Federal do Ceará (UFC). Instituição: Universidade de Fortaleza (UNIFOR)

Endereço: Fundação Edson Queiroz - Universidade de Fortaleza, endereço: Av. Washington Soares, 1321 - Edson Queiroz - CEP 60811-905 - Fortaleza-CE Brasil.

E-mail: magdalaborja@gmail.com

\section{Eduardo Nunes Freire}

Mestre em Comunicação e Cultura Contemporânea pela Universidade Federal da Bahia (UFBA) e Professor da Universidade de Fortaleza. Graduado em Jornalismo pela Universidade Federal do

Ceará (UFC).

Instituição: Universidade de Fortaleza (UNIFOR)

Endereço: Fundação Edson Queiroz - Universidade de Fortaleza, endereço: Av. Washington Soares, 1321 - Edson Queiroz - CEP 60811-905 - Fortaleza-CE Brasil.

E-mail: eduardonfreire@unifor.br

\section{RESUMO}

Com base num estudo anterior referente à cobertura da guerra civil em Angola de 1975 pelos jornais brasileiros, O Estado de S. Paulo e a Folha de S. Paulo, o Artigo procura destacar o papel do jornalismo de guerra, que vem mitificando a profissão do jornalista. Conforme as referências bibliográficas, apresenta-se uma comparação de significado da palavra "guerra" para um angolano e um brasileiro, cuja percepção é variável por conta do contexto histórico, social, político e democrático em que as situações de conflito foram ocasionadas.

Palavras-Chave: Jornalismo de guerra, Guerra, Angola, Brasil.

\begin{abstract}
Based on a previous study references to the coverage stance taken by two São Paulo newspapers, $O$ Estado de S. Paulo and Folha de S. Paulo, when writing about the 1975 civil war in Angola. This scientific paper seeks to highlight the role of war journalism, which has been mitigating the profession of journalist. According to the bibliographic references, the word 'war' has contrast of meaning when introduced to an Angolan and a Brazilian citizen, because the perception is variable due to the historical, social, political and democratic context in which the conflict situations were build.
\end{abstract}

Keywords: War Journalism, War, Angola, Brasil. 


\section{INTRODUÇÃO}

Graças à cobertura noticiosa de cenários de guerra, a profissão de jornalista tem se mitificado. As matérias de guerra, grande parte delas, transformam-se em documentos jornalísticos de enorme importância, que vão marcando gerações de repórteres e aspirantes. Exemplo disso: Mais um dia de vida: Angola 1975, de Ryszard Kapuscinski; Hotel Babilónia, de Cáceres Monteiro; A verdade da Guerra, de José Rodrigues dos Santos; O inverno de Guerra, de Joel Silveira, e O gosto da Guerra, de José Hamilton Ribeiro. É uma das táticas de averiguação que se exige a mediação jornalística de um profissional de comunicação.

A história do jornalismo revelando vários valores fluidos e flexíveis na concepção do que é informação de interesse público. Em tempos de convergência mediática, o próprio conceito de investigação jornalística/mediação está-se alterando e refletindo no papel do jornalista. Vem se questionando qual seria o papel do jornalista com o aparecimento dos novos media. Deste modo, o jornalista foi-se adaptando às sucessivas mudanças de "transmissão entre as instituições e as audiências, vigilante do bom funcionamento dessas instituições e intérprete dos sinais da realidade" (SZYMANIAK, 2000, p.139).

Sob este ponto de vista, o presente estudo baseia-se numa pesquisa monográfica realizada em 2009, como trabalho de Conclusão de Curso de Magdala Borja. Trata-se de uma monografia onde a autora analisa o posicionamento discursivo utilizado pelos jornais paulistanos, $O$ Estado de $S$. Paulo e a Folha de S. Paulo, quanto à guerra civil de Angola de 1975.

Os dois periódicos contam com grandes profissionais de comunicação, que garantem o tempo de existência, a ampla circulação e o sucesso nacional e internacional (nos dias atuais). Mas, será que a cobertura da guerra civil empregado por estes jornais contribuiu para este olhar de uma Angola ainda sob o baixo fogo?

Este artigo procura destacar as variações que existem para cada indivíduo/Estado/Região/País que enfrenta uma guerra, ou seja, a perspectiva quanto ao termo jamais será a mesma. Assim, explica-se por que um angolano não terá o mesmo olhar sobre determinada guerra comparando com olhar dum brasileiro, por exemplo.

\section{JORNALISMO DE GUERRA}

O Jornalismo de Guerra, nos dias de hoje, é reportagem em tempo real. Além de desafiar o profissional de comunicação também instiga o leitor a "ver", que há conflitos no mundo que mudam de forma rápida, com resultados imprevisíveis e às vezes catastróficos, que parece não existir mais possibilidade de retorno. 
A Segunda Guerra Mundial (1939 - 1945) foi uma das maiores inovações do jornalismo internacional brasileiro. O conflito contou com a cobertura jornalística de Joel Silveira (correspondente dos Diários Associados), Egydio Squeff (correspondente d'O Globo), Rubem Braga (Diário Carioca), Raúl Brandão (Correio da Manhã) e o fotógrafo Thassilo Mitke. Lembrando que, segundo Vicentino e Dorigo (1997), Brasil participou diretamente da guerra enviando para a Itália um contingente militar, a Força Expedicionária Brasileira (FEB). Nesta altura, o país era governado pelo presidente Getúlio Vargas (1951-1954), que "trocou uma participação mais ativa do Brasil na guerra pela Usina de Volta Redonda” (VICENTINO e DORIGO, 1997, p. 372).

$\mathrm{Na}$ verdade, o correspondente dos Diários Associados, Joel Silveira cobriu a Segunda Guerra Mundial junto aos postos da FEB da Itália. Em entrevista a Sylvia Colombo ${ }^{1}$, o jornalista afirmou que "Estávamos mais distantes dos fatos sensacionais do mundo do que qualquer carioca ou paulista". Para Colombo (idem) os jornalistas brasileiros “[...] Retrataram personagens, paisagens, gostos e reações de tal maneira que entregavam a quem os lesse instrumentos para que construíssem um cenário vivo dos conflitos".

No período da Segunda Guerra Mundial, Brasil vivia sob a ditadura do Estado Novo (1937-1945). Conforme Silveira “2 “Qualquer menção às palavras democracia ou liberdade era motivo para o texto cair". Assim, de jornalismo internacional, Brasil passou a contar com um novo modelo de jornalismo... o de Guerra.

A Ditadura Militar brasileira (1964 a 1985) também foi outro fator que modificou o jornalismo internacional. Porque as pautas censuradas no Brasil eram abordadas no caderno de Exterior.

Com pautas tão amplas e de certo modo as únicas a levantar essas questões nas redações brasileiras, as editorias de Política internacional despertavam durante o regime militar um interesse inédito junto ao cidadão-leitor. Isso ocorreu sobretudo durante os chamados "anos de chumbo" do governo Médici. (NATALI, 2004, p.50)

A forma que é denominada gera certas controvérsias, para uns foi mais uma campanha do que uma guerra. Para o jornalista brasileiro José Hamilton Ribeiro (2005), a guerra de Canudos tratou-se de mais um eufemismo, no sentido de que ela não foi propriamente uma guerra comparada com a guerra do Vietnã que ele mesmo vivenciou em 1968, mas sim um conflito social em busca de melhores condições.

${ }^{1}$ Copyright Folha de S. Paulo, 05/05/2005.

${ }^{2}$ Apud COLOMBO, copyright Folha de S. Paulo, 05/05/2005. 
Não é possível falar de cobertura de guerras no Brasil sem citar a Guerra de Canudos (1896 a 1897). Ela foi um dos primeiros passos do jornalismo de guerra brasileiro. Euclides da Cunha a serviço do jornal O Estado de S. Paulo, conseguiu reunir material para uma série de reportagens, durante cinco anos, que posteriormente deram origem à sua obra-prima, Os Sertões: campanha de Canudos (1902). Não se deve desconsiderar este conflito como um marco do jornalismo de guerra brasileiro, pois ela representou o descaso dos governantes com relação aos grandes problemas sociais do país, e é assim que ela deve ser "sentenciada":

A campanha de Canudos tem por isto a significação inegável de um primeiro assalto, em luta talvez longa. Nem enfraquece o asserto o termo-la realizado nós filhos do mesmo solo, porque, etnologicamente indefinidos, sem tradições nacionais uniformes, vivendo parasitariamente à beira do Atlântico, dos princípios civilizadores elaborados na Europa, e armados pela indústria alemã - tivemos na ação um papel singular de mercenários inconscientes. Além disto, mal unidos àqueles extraordinários patrícios pelo solo em parte desconhecido, deles de todo nos separa uma coordenada histórica - o tempo. (CUNHA, 2008, p. 20)

Canudos é um exemplo de cobertura de uma guerra civil não declarada. Outro exemplo de guerra civil não declarada é a guerra urbana $^{3}$, que hoje se trava nas cidades brasileiras. Ela tem causado maior número de mortes do que foi contabilizado durante a guerra civil em Angola, por exemplo. Não que se esteja a fazer uma comparação efetiva, até porque são dois casos completamente distintos (Guerra civil angolana versus cidades dominadas por bandidos e traficantes). Na verdade, os objetivos, as estratégias, a delimitação dos campos de atuação e dos protagonistas são totalmente diferentes. O que há, em certos lugares do Brasil não é exatamente uma guerra, pois não existe nenhum interesse de tomada de poder por parte dos traficantes para controlar o país e serem reconhecidos como governantes e dirigir o destino do povo. Os interesses são outros: corromper a sociedade, obter lucro e dominar áreas para manutenção de seus negócios. Porém, considera-se que os efeitos sejam os mesmo de uma guerra civil.

A presença dos jornalistas na cobertura das guerras do tráfico nas cidades aproxima-se em muito das coberturas de outros conflitos armados mundo a fora.

O que está em análise é o fato de se afirmar continuamente que Brasil tem poucos casos de guerra. Mas, numa pesquisa anterior referente aos discursos empregados pelos dois jornais

\footnotetext{
${ }^{3}$ Guerra urbana caracteriza-se por ondas de conflito entre os moradores das favelas e a Polícia Militar. Segundo o Conselho de Direitos Humanos das Nações Unidas sobre Execuções Arbitrárias, Sumárias ou Extrajudiciais, divulgado em 2008, Brasil tem mais do que "o dobro da taxa média de homicídios no mundo" (apud Site Terra Magazine). A circunstância resulta da guerra urbana, também conhecida como guerra invisível, que se vem travando nas principais metrópoles do país.
} 
paulistanos, O Estado de S. Paulo e a Folha de S. Paulo quanto à guerra civil em Angola de 1975, constatou-se que teoricamente Brasil teve mais casos de guerra comparando com o país africano.

Reconhece-se que não é fácil indicar um conceito absoluto para a palavra "Guerra", pois sempre fomos influenciados por ideologias e persuasões. Segundo Szymaniak (2000, p.124) ideologia é um "Conjunto de idéias sociais, econômicas, ou religiosas que interferem na produção das mensagens e na criação de significações”. Ou seja, ela exerce, com freqüência, o seu domínio sobre a comunicação, seja diretamente ou por imposição da censura, seja de forma indireta, pela criação de conotações e pelo apoio nos mitos. Já a persuasão, conforme explica Szymaniak (2000, p.184), é uma "Ação comunicativa orientada na modificação " voluntária " do comportamento ou atitude do interlocutor ou de um público. Pode ser direta ou oculta. Freqüentemente tem ação retardada".

Deste modo, é complicado definir de maneira concreta o que consiste a palavra "Guerra", pois o indivíduo é influenciado por um dos termos já descritos. Conforme Bonanate (2001, p.21):

Por incrível que pareça, o conhecimento que temos acerca do que seja guerra é extraordinariamente limitado, e quanto mais importante nos parece conseguir aprofundá-lo saber mais sobre esse que é, na história da humanidade, o evento de mais exíguo ele se torna.

E vai ressaltando (BONANATE, 2001, p.75) que:

(...) a guerra é algo ainda mais complexo do que uma arte ou uma ciência, estando ela tão estreitamente ligada à política que, assim como nesta, o que seria importante revelar é a natureza, as regras verdadeiras, as leis ou as exceções, para compreender as causas e eventualmente agir sobre elas.

Sob o olhar da pesquisa realizada quanto à cobertura da guerra civil de Angola pelos jornais $O$ Estado de S. Paulo e a Folha de S. Paulo, entende-se pela forma que a guerra aconteceu em Angola, a população deste país tem um conceito diferenciado de outros países que passaram pela mesma situação. Pois, cada combate ou bombardeamento é uma experiência que cada indivíduo, por infelicidade, vive do seu jeito.

A concepção de guerra para um vietnamita é diferente de um israelita, assim como um timorense tem uma visão diferente de um afegão ${ }^{4}$. Assim sendo, cada caso de guerra remete para uma experiência mais extremas da condição humana. Tal como explica Rodrigues dos Santos "Quem

\footnotetext{
${ }^{4}$ Neste trecho está-se a salientar o tempo de guerra vivido dentro de cada país (Guerra do Vietnã, 1965-1975; Guerra do Iraque, 2003 - até o presente; Guerra do Timor-Leste, 1999-2002; Guerra do Afeganistão, 1979 - até o presente).
} 
viveu um combate não esquece a experiência, justamente porque a guerra desperta reacções insuspeitadas das profundezas da mente" (2005, p.135).

\section{A COBERTURA DA GUERRA EM ANGOLA NO BRASIL}

Angola viveu longos anos de guerra civil. Há quem compare a história desse período dos angolanos à guerra do Vietnã, mas como foi ressaltado, cada caso tem o seu próprio contexto e significação. No ano de 1975, a tragédia abateu-se em todo o território angolano. Os três Movimentos de Libertação $\left(M_{P L A}^{5}\right.$, FNLA $^{6}$ e UNITA $^{7}$ ) não foram capazes de criar uma tropa mista para proclamar a independência da república. Em vez da união, cada movimento preferiu reforçar próprias fileiras, munir-se de armamento estrangeiro e mobilizar todos os seus efetivos.

Quem estava em Angola vivia tempos cruéis e de desordem profunda. A população civil foi quem mais sofreu com os transtornos da guerra fratricida. Ninguém queria permanecer no país em estado catastrófico. Segundo Kapuscinski (2007, p.85), o angolano que viveu a guerra tem nela a imagem de confusão. Isto é:

A confusão é um estado de desorientação absoluta. As pessoas que dão consigo dentro da confusão não conseguem compreender o que se passa à sua volta ou dentro delas mesmas. Também não são capazes de explicar especificamente o que causou este caso particular de confusão. Há portadores do vírus da confusão de quem as outras pessoas se devem acautelar, embora isto não seja difícil, porque qualquer um pode, a qualquer momento, tornar-se perpetrador de confusão, mesmo contra a sua vontade. A confusão também se refere aos nossos próprios estados de perplexidade e impotência. Vemos confusão a espalhar-se à nossa volta e nada podemos fazer para impedir o seu avanço. Camaradas, ouvimos dizer vezes sem conta, não criem confusão - por favor! Mas será que depende de nós? O relato mais preciso da frente de combate: - Quais são as novidades? - Confusão! Todos os que compreendem esta palavra conhecem a história toda. A confusão pode reinar sobre um enorme território e tomar milhões de pessoas. Então dá-se a guerra. Um estado de confusão não pode desfazer-se de um golpe nem desaparecer num abrir e fechar de olhos. Quem o tentar, cai ele mesmo na confusão. O melhor é agir com calma e esperar. Ao fim de algum tempo, a confusão perde energia, enfraquece, desaparece. Saímos de um estado de confusão exaustos, mas de certa forma satisfeitos por termos conseguido sobreviver. Começamos de novo a fazer reservas de energia para a confusão seguinte.

Vale frisar que, esta teoria de confusão defendida por Kapuscinski, possivelmente, terá sido adotado no mundo todo na esteira da Guerra Fria. Na verdade, com a guerra fria, o mundo passava, nas palavras de Winston Churchil (primeiro-ministro britânico, 1940), para o "equilíbrio instável do terror", um traço que com certeza trouxe seqüelas psíquicas para gerações seguintes.

\footnotetext{
${ }^{5}$ Movimento Popular de Libertação de Angola, de tendência marxista. Na altura era dirigido por Agostinho Neto. Partido que proclamou a independência de Angola.

${ }^{6}$ Frente Nacional de Libertação de Angola, de feição socializante moderada. Liderada por Holden de Roberto.

${ }^{7}$ União para a Independência Total de Angola considerava-se neutra. E, era dirigida por Jonas Savimbi.
} 
De fato, Brasil é um país quase sem histórico de guerra de grande magnitude. Isto quer dizer que muito daquilo que ocorreu no território brasileiro não teve a dimensão das catástrofes comparando com os demais países que viveram situações de guerra. Mas, essa concepção de que o Brasil seja um "país quase sem guerra" entra em certo desequilíbrio, tal como divulga o site Terra Magazine (2009) $)^{8}$ :

O mito de país pacífico se confronta com as ruas, os medos, o cotidiano dos brasileiros. Uma constatação atravessa as diferentes bases de dados oficiais: o número de homicídios expõe uma guerra urbana invisível, quando muito exibida em sua face minúscula em sites, revistas, rádios, televisões e jornais. A cordialidade aparente do Brasil e das suas metrópoles não subsiste aos números da violência. Uma guerra por década. Uma só guerra por décadas.

$\mathrm{Na}$ pesquisa que originou este artigo, Borja (2009) salienta que na cobertura da guerra civil de Angola pelos jornais $O$ Estado de S. Paulo e a Folha de S. Paulo, houve sim, alguns conflitos pelo qual a população brasileira se deparou. Conflitos esses que muitas vezes foram restritos a determinado território nacional, e que não deixaram muitas evidências no presente. Havendo momentos em que as divergências foram resolvidas em território estrangeiro, é o caso da Guerra do Paraguai. Foram enumeras as guerras e/ou conflitos brasileiras, que não cabe aqui mencionar-las, pois não se tratam do foco desta pesquisa.

Apesar de falarem a mesma língua, as experiências de guerra vivida por cada país foram em tempos diferentes: em Angola, os Movimentos de Libertação cobiçavam o poder pleno do país com a proclamação da independência, em 1975, mas novos conflitos surgiram com a conquista dela. Já, Brasil tinha o forte desejo de ver cumprido os seus direitos, em qualquer uma das suas circunstâncias de guerra vivida no país. Como tal, é um absurdo afirmar que "Toda guerra é absurda", para a quebra deste tabu existe o jornalismo de guerra com o propósito de enfrentar certos constrangimentos para nos relacionar com o mundo.

A guerra civil de Angola de 1975 caracterizou-se como um fato jornalístico de relevância mundial em toda a sua conjuntura. Mesmo com a insuficiência dos meios de comunicação, o tempo jornalístico estava voltado para a estrutura daquele acontecimento, que foi a luta para a proclamação da república popular de Angola.

Na metade do século XX, o impacto exercido pela II Guerra Mundial impulsionou o processo de descolonização (COUTO e ROSAS, 2001, p. 220), visto que:

\footnotetext{
${ }^{8}$ Disponível em: <http://terramagazine.terra.com.br/interna/0,,OI3818596-EI6578,00-Brasil+uma+guerra+urbana.html〉. Acesso em 13 de set. 2009.
} 
- A guerra abalou a solidez dos impérios europeus - Na Ásia, o Japão tornou-se potência local, sem que os colonizadores europeus o conseguissem impedir. "Nem mesmo a sua posterior derrota frente ao poderio americano foi capaz de restabelecer o prestígio da Europa na região" (Idem).

- A guerra "acordou” os dominados - “A incorporação de contingentes das colônias ${ }^{9}$ nos exércitos aliados contribuiu para a tomada de consciência da injustiça do sistema colonial”.

- A guerra exigiu dos territórios coloniais pesados sacrifícios - "contribuindo para aumentar o descontentamento contra o dominador estrangeiro". E, como foi óbvia, a guerra fragilizou, em termos econômicos e políticos, os Estados europeus - fim da guerra, os europeus se vêem em "contestação anticolonialista que não conseguem, com êxito, contrariar".

Em Angola, a divisão dos pólos aglutinados reacendeu o sentimento de nacionalismo dos partidos nacionais que procuraram "intimidar" os colonizados. Os Movimentos Nacionalistas tinham a finalidade de recuperar a identidade cultural e nacional dos povos colonizados. Foram três partidos políticos que mais se destacaram em Angola, sendo eles: o MPLA (Movimento Popular para Libertação de Angola, que tinha como líder Agostinho Neto de tendência marxista), a FNLA (Frente Nacional para Libertação de Angola, liderada por Holden Roberto, de feição socializante moderada) e a UNITA (União Nacional para Independência Total de Angola, tendo como líder Jonas Savimbi, afirmando se como neutra).

Mesmo com todo o impasse da guerra, Angola foi proclamada, a 11 de novembro 1975, um país independente pelo MPLA. O partido era liderado por Agostinho Neto e foi somando credibilidade. Em 23 de fevereiro de 1976, Portugal reconheceu-o quando se encontrava já legitimado por 81 países.

Uma vez independente, a Guerra Civil em Angola continuou. "A recusa da UNITA em reconhecer a derrota no acto eleitoral de 1992, previsto pelos acordos de Bicesse e fiscalizado pela ONU, reacendeu o conflito". (COUTO e ROSAS, 2001, p. 285). O povo angolano viveu desde o início da guerra colonial, em 1961, um clima de guerra permanente, até manter a sua soberania e integridade territorial e conquistar finalmente a paz no dia 4 de abril de 2002.

Os demais processos de descolonização africana foram marcados por guerras sangrentas, mas o caso mais grave foi o de Angola. Em nenhum momento as dificuldades deixaram de crescer: os três movimentos de libertação nacional (MPLA, UNITA e FNLA) foram incapazes de superar os seus antagonismos.

\footnotetext{
9 “Os britânicos mobilizam 2 milhões de indianos; os franceses recrutaram 275000 norte - africanos e 175000 soldados da África Negra” (COUTO e ROSAS, 2001, p. 220).
} 
Era previsto na altura da transição de poderes (do poder português para o poder angolano) à constituição de forças armadas mistas. Em vez disso, cada movimento de libertação angolana reforçou as suas próprias fileiras, munindo-se de armamento estrangeiro e mobilizando todos os seus efetivos.

Nesses anos de 1970, os meios de comunicação eram limitados e em alguns casos tendenciosos, ainda mais com a crise econômica nos países industrializados ocidentais. Não havia na época a convergência mediática, que temos tido a assistir, por exemplo, a internet (um espaço áudioscripto-visual). Na verdade, alguns profissionais faziam uso dos veículos de comunicação para denegrir a imagem do rival, eram atos de pura propaganda.

Com todo o clima de hostilidade, provocado pelo antagonismo dos três movimentos de libertação, todos aqueles que podiam fugiam de Angola. Contudo, não faltaram jornalistas decididos a ir para lá, eis o exemplo do polaco Ryszard Kapuscinki ${ }^{10}$.

Assim como Angola, Brasil é um país pluriétnico. Além de serem países que possuem na sua essência a diversidade e compartilharem a mesma língua, o português; ambos estão intimamente ligados pela história.

A maior parte dos negros do Brasil é oriunda da costa ocidental africana. E nessa leva, segundo Ribeiro (2005) o terceiro grupo cultural africano veio de Angola, no qual era integrado por tribos Bantus.

\begin{abstract}
A contribuição cultural negra foi pouco relevante na formação daquela protocélula original da cultura brasileira. Aliciado para incrementar a produção açucareira, comporia o contingente fundamental da mão-de-obra. Apesar do seu papel como agente cultural ter sido mais passivo que ativo, o negro teve uma importância crucial, tanto por sua presença como a massa trabalhadora que produziu quase tudo que aqui se fez, como por sua introdução sorrateira mas tenaz e continuada, que remarcou o amálgama racial e cultural brasileiro com suas cores mais fortes. (Ribeiro, 1995, p.114)
\end{abstract}

Apesar de viver tempos de hostilidade com a Ditadura Militar, Brasil foi um dos primeiros países a reconhecer a independência unilateral proclamada pelo MPLA em Angola, no dia 11 de novembro de 1975. E, também procurou publicar matérias "inéditas" e "exclusivas" para que se tenha uma noção do que consistiu a guerra civil em Angola. É o caso dos profissionais de comunicação dos jornais paulistanos $O$ Estado de S. Paulo e Folha de S. Paulo.

O repórter Herbert Matthews (apud Rodrigues dos Santos, p. 135 e136) diz que quem nunca viu uma batalha, a sua educação foi de algum modo negligenciado. Para ele, "É que, afinal, a guerra sempre foi uma das funções primárias da humanidade, e, a menos que tenha visto homens a

\footnotetext{
${ }^{10}$ Kapuscinski foi considerado um dos grandes mestres do jornalismo moderno, foi eleito em 1999 o melhor jornalista polaco do século XX e distinguido, em 2003, com o Prêmio Príncipe das Astúrias de Comunicação e Humanidades.
} 
combater, você perdeu algo fundamental”. O que quer dizer que, a guerra permite, quando se quer, um processo de autoexploração, de conquista e de descoberta, e é justamente esse processo que exerce um tão poderoso fascínio (Rodrigues dos Santos, 2005).

Em tempos ameaçadores, Angola torna-se independente e o mundo estava a par dessa data histórica, 11 de novembro de 1975. Conforme Borja (2009) julga-se de extrema importância pontuar de que forma os dois jornais paulistanos, O Estado de S. Paulo e a Folha de S. Paulo relataram aos seus leitores sobre o grande acontecimento para todos os angolanos, e não só.

O Estado de S. Paulo publicou 55 matérias, sendo que foram analisadas 51 devido as péssimas condições de serem lidas. O Estadão possui 12 matérias assinadas por enviados especiais do próprio jornal, outras duas são copyright do jornal L'Express, uma é da autoria do jornalista C. L. Sulzberger do $N$. Y. Times e as restantes matérias não trazem assinatura. O fluxo de informação do periódico, como o número indica, não segue uma seqüência diária, entre uma notícia e outra há a durabilidade de um dia a quatro dias. Mas a cada publicação ele foi frisando todos os acontecimentos para que o leitor ficasse sempre por dentro do caso da guerra civil em Angola de 1975. O jornal informa sobre a crise política, depois relata a chacina entre os três movimentos de libertação angolana e, de modo bem desenvolvido, explica o envolvimento dos países estrangeiros, ora favoráveis para o fim da guerra ora para alimentar ainda mais as diferenças partidárias. Segundo Borja (2009) as matérias d'O Estado de S. Paulo visavam contextualizar, descrever, informar e pontuar os fatos do conflito civil. Já as matérias assinadas, além do caráter informativo, procuravam esclarecer os dados e pontuar questões bastante reflexivas. Por exemplo, o MPLA era o partido com o maior número de cidades sob o seu controle, e o jornal produziu uma matéria onde descreve quem é o líder do partido rival UNITA, Jonas Savimbi. Na verdade, o jornalista faz uma apresentação do partido, mas o objetivo central consiste que o leitor reflita quanto ao fato se existe alguma possibilidade de se ser neutro num país em guerra. O jornalista J. M. Pereira da Costa, representando o jornal Estadão, descreve Savimbi como alguém misterioso, um caso a ser desvendado. E, isso é bem característico das matérias desse jornal. Fica-se com a impressão que o Estadão vai desvendar ou revelar determinado fato, mas no fim ele deixa entreaberta outra questão.

Em suma, segundo Borja (2009) o posicionamento discursivo do jornal O Estado de $S$. Paulo ajusta-se à perspectiva que ele mesmo criou, "preocupação com a verdade".

Talvez seja esse um dos motivos que levou o jornal a preferir publicar parte das matérias assinadas pelos enviados especiais da sede. Tanto mais que a primeira matéria publicada quanto à guerra angolana, o jornal teve o cuidado de informar que a publicação anterior teria errado no número de vítimas dos distúrbios sucedido em Luanda: "Ao contrário do que se anunciou anteriormente, foram dez e não trê vítimas dos distúrbios de segunda-feira: dois oficiais portugueses, três soldados da Frente Nacional de Libertação de Angola (FNLA), um 
integrante do Movimento Popular de Libertação de Angola (MPLA) e maior o temor de uma guerra civil" (extrato da matéria "Agrava-se a crise política em Angola", publicado no dia 05 de fevereiro de 1975). (BORJA, 2009, p.78)

Já o jornal Folha de S. Paulo, publicou 123 matérias alusivas à guerra civil de Angola de 1975. Borja (2009) afirma que as matérias eram oriundas de agências de notícias e publicações de outros jornais estrangeiros. Os artigos e informações fornecidas à Folha pertenciam à Tass, France Press, ANSA e UPI. Dos jornais estrangeiros o fluxo de informação provinha de Le Monde, New York Times, Pravda (órgão do partido comunista da URSS), Miami Herald, Daily News da Tanzânia, Salongo do Zaire, Washington Post, Financial Times, Johannesburgo Star, Sunday Express, Expresso e Diário do Povo de Pequim. E outras matérias apenas vêm com o local de origem da informação, mas não salientam se pertencem a agências de notícias ou jornais estrangeiros.

"[...] presume-se que a posição ideológica da Folha de S. Paulo já tenha sido filtrada pelos outros jornais e agências do qual adquiriu as informações. Este aspecto da possível interferência de posicionamento de um meio de comunicação para outro, ocorre imensas vezes no mundo mediatico, o que existe aqui é apenas um pequeno exemplo". (BORJA, 2009, p.57)

A Folha procurou empregar uma linguagem que informasse, atualizasse, explicasse e pontuasse os fatos. Mas, Borja (2009) afirma que houve espaço para denúncias, críticas, pânico e apelações.

"[...] esses objetivos de discurso eram representados mais pelos movimentos de libertação angolana, as intervenções estrangeiras e as próprias agências de notícias que divulgavam as informações. As matérias assiandas pelos correspondentes da Folha tinham como objetivo expressar uma opinião e uma visão daquilo que estava a acontecer em Angola". (Idem, p.58)

$\mathrm{Na}$ pesquisa de 2009, Borja apresenta como exemplo a matéria assinada por um correspondente diplomático, Flávio de Almeida Salles. Automaticamente, a matéria, "O Brasil não acredita em guerra civil" (publicado no dia 17 de julho de 1975), adquire um peso e um investimento de poder/autoridade e até mesmo maior credibilidade, pela imagem e condição de ser diplomata que enfatiza uma idéia para a identidade do jornal.

Borja (2009) afirma que, desde o momento que o jornal Folha de S. Paulo assumiu o compromisso de divulgar matérias sobre a guerra fratricida de Angola de 1975, ela cobriu o conflito mantendo um distanciamento face às partes envolvidas.

Julga-se que a Folha de S. Paulo tenha direcionado o seu foco exclusivamente em noticiar o que estava a acontecer, por isso teve preferência em ser assinante das agências de notícias e dos jornais estrangeiros. Mas, claro, num dado momento o jornal se posicionou quanto à guerra. Com base nas duas matérias assinadas pelos correspondentes do jornal, é possível 
afirmar que a Folha de S. Paulo estava consciente da importância de Angola como um dos principais países africanos. Mas, para a Folha, o conflito era ilógico, no qual os três movimentos de libertação nacional não apresentavam soluções plausíveis para a massa populacional. (Ibidem, p.79)

No caso particular do jornal Folha de S. Paulo nota-se que para ele a guerra civil angolana era uma questão de tempo de proclamar a independência e tomar o poder da república. Por isso, ela procurou manter uma postura bastante neutra, divulgando aquilo que o mundo tinha agendado como preferência das manchetes africanas.

Estudos dessa natureza demonstraram quanto é fundamental à profissão de um jornalista de guerra, pois além de trazer novas visões, ela pontua questões relevantes de determinada guerra.

Em suma, a guerra passa para quem a cobre e a segue uma sensação heróica quando é superada. Pode parecer negligente por conta de todos os destroços que surgem nas zonas de conflito. Mas, o trabalho se prepôs a demonstrar que nenhuma guerra é absurda, e é o jornalismo de guerra que aparece com o propósito de enfrentar certos constrangimentos para nos relacionar com o mundo.

Enfim, cada indivíduo/Estado/Região/País a denomine como quiser guerra/luta/campanha/conflito, mas o que deve ser acentuado é que o jornalismo de guerra mudou e continua a mudar o rumo da história do jornalismo em qualquer parte do Planeta, graças a ela a profissão de jornalista é mitificada.

\section{CONSIDERAÇÕES FINAIS}

Se questionarmos alguém que não tenha nascido ou vivido nesses dois países, Angola e Brasil, seria provável que o primeiro país fosse associado a um território ainda em guerra, e o segundo teria outra avaliação. Por isso, o foco central desta pesquisa consistiu em analisar o posicionamento discursivo utilizado pelos jornais $O$ Estado de S. Paulo e a Folha de S. Paulo quanto à guerra civil de Angola em 1975. Na verdade, ainda há pessoas no Brasil que acreditam que Angola vive sob baixo fogo, enquanto que a realidade é outra. Angola é um dos países africanos que tem se desenvolvido vertiginosamente. E, é deste ponto que surge o problema da pesquisa da monografia "Será que os discursos empregados pelos dois jornais, O Estado de S. Paulo e a Folha de S. Paulo, influenciaram, de algum modo, para essa visão de Angola ainda em guerra?”.

A pesquisa faz um olhar provocativo nas matérias publicadas pelos jornais mencionados. Eles são muito prestigiados quanto ao critério de circulação no país, e hoje em dia têm alcançado além-fronteiras. Mas, esse mérito de serem os jornais mais requisitados do país existe graças aos grandes profissionais de comunicação que garantem o sucesso jornalístico de cada jornal. Sem a 
atuação deles, cada um com a sua postura e ideologia, esses anos de existência jamais podiam prevalecer.

Contudo, subsiste um país que se assume com poucos casos de guerra, Brasil. Essa colocação permite dizer que as práticas discursivas utilizadas pelos jornais, poderiam ter feições que ressaltassem mais o caos, a tragédia e o clima hostil de Angola de 1975, fazendo com que essas marcas se mantivessem na memória de muitos leitores brasileiros. Pois, a concepção de guerra, como já foi explicada, desperta reações que variam de pessoa para pessoa.

Não é uma critica que se está a fazer aos dois jornais, pelo contrário, a cobertura deles foi fundamental para o entendimento geral do que estava a acontecer em Angola. Embora fizessem uso de matérias publicadas por outros jornais e agências internacionais. Já a Folha de S. Paulo publicou 123 matérias, todas elas fornecidas por agência de notícias e jornais internacionais. Tal como consta na pesquisa anterior, presume-se que a posição ideológica da Folha a respeito da guerra civil de Angola já estava filtrada pelos outros jornais e agências do qual adquiriu as informações, pois não foi para o país africano cobrir diretamente o conflito.

O objetivo geral, para tal pesquisa, consistiu em revelar de forma criteriosa (para o tempo exigido para se escrever uma monografia) a visão dos dois jornais paulistanos quanto à guerra civil angolana. Com base na metodologia da análise de discurso francesa, num levantamento rigoroso e nas grandes referências bibliográficas a respeito do tema nota-se que houve o empenho de se aprofundar e avaliar o posicionamento discursivo utilizados pelos jornais $O$ Estado de S. Paulo e Folha de S. Paulo na construção dos sentidos referente à guerra civil de Angola. Porém, ainda pode ser reavaliado de modo mais restrito em uma dissertação de mestrado. Pois, é um tema que envolve uma riqueza de interpretações. 


\section{REFERÊNCIAS}

BONANATE, Luigi. A Guerra. São Paulo: Estação Liberdade. 2001.

BORJA, Magdala A. T. Vaz. A Cobertura da Guerra Civil em Angola pelos Jornais $\boldsymbol{O}$ Estado de S. Paulo e Folha de S. Paulo: Uma análise de Discurso. Monografia. Curso de Comunicação Social - Jornalismo. Universidade de Fortaleza. Fortaleza. 2009.

COLOMBO, Sylvia. Cobertura de Guerra. In: Entre Aspas. 2005. Disponível em: http://observatorio.ultimosegundo.ig.com.br/artigos.asp?cod=327ASP017. Acesso em 07 de setembro de 2009.

COUTO, Célia Pinto do e ROSAS, M. a Antônia Monterroso. O Tempo da História. Porto: Porto Editora. 2001.

CUNHA, Euclides. Os Sertões. Edição eBooksBrazil. 2008. Disponível em:

<htt:/ /www.scribd.com/doc/3237639/Os-Sertoes/>. Acesso em 07 de setembro de 2009.

KAPUSCINSKI, Ryszard. Mais um dia de vida: Angola 1975. Porto: Campo de Letras - Editores, S.A. 2007.

RIBEIRO, Darcy. O Povo Brasileiro: a formação e o sentido do Brasil. $2^{\text {a }}$ Ed. São Paulo: Companhia de Letras. 2005.

RODRIGUES DOS SANTOS, José. A Verdade da Guerra: da subjetividade, do Jornalismo e da Guerra. $6^{\text {a }}$ edição. Lisboa. Gradiva. 2005.

SZYMANIAK. Wlodzimierz Jozef (coord.). Dicionário de Ciências da Comunicação. Porto: Porto Editora. 2000.

TERRA MAGAZINE. Brasil: uma Guerra Urbana. 2009. Disponível em: <http://terramagazine.terra.com.br/interna/0,,/OI3818596-EI6578,00-

Brasil+uma+guerra+urbana.html>. Acesso em 09 de setembro de 2009.

VICENTINO, Cláudio e DORINGO, Gianpolo. Histórias do Brasil. São Paulo: Editora Scipione. 1997. 